\title{
India seeks scientific basis of traditional remedies
}

New Delhi

TAKING its cue from China, India has launched a scheme for placing timehonoured traditional remedies on a scientific footing, in collaboration with laboratories in the West.

Indians have been using herbal medicines for centuries without knowing why they are effective. The most promising traditional medicines will now be subjected to Western scrutiny, laboratory research and clinical trials, and those that pass the tests will be earmarked for production.

One drug was released last month by $\mathrm{Mr}$ Rajiv Gandhi, the prime minister. Called 'guggulipid', the potent cholesterol-reducing drug has been derived from the extract of 'commiphora mukul', a plant mentioned in the ancient medical system of Ayurveda. Developed by the Central Drug Research Institute and now manufactured by a private drug company, gug- gulipid is said to be the first major gift of Ayurveda since reserpin, the cardiac drug derived from snakeroot (Rauwolfia serpentina). Similarly, a cervical dilator made from seed husks of isubgol (Plantogo ivata) has completely displaced from the Indian market the laminaria tent, the product of a Swedish company.

Six promising traditional remedies are under Western scrutiny, according to Dr S. Satyavati, deputy chief of the Indian Council of Medical Research (ICMR), who is directing the scheme for resurrecting time-tested herbal cures under the Ayurveda, Unani and Sidha systems. Ayurveda lists 341 plants with medicinal properties and the other two prescribe remedies based on plants as well as inorganic minerals.

India has 275,000 traditional practitioners, and there are 1,600 hospitals and 13,000 dispensaries offering traditional health care. The indigenous systems claim

\section{Japanese plans to sequence human genome}

Tokyo

JaPAN's Science and Technology Agency has taken its first formal step towards setting up a programme for sequencing the human genome.

The agency, in collaboration with Seiko and Fuji Film, has for several years been developing an automatic DNA-sequencing machine under the leadership of Professor Akiyoshi Wada of Tokyo University (see Nature 325,$771 ; 1987)$, and a move to begin processing long DNA sequences, such as the human genome, has been expected.

On 12 March, the biotechnology subcommittee of the agency's Council for Aeronautics, Electronics and Other Advanced Technologies held a meeting to set up a working group. The subcommittee, under the chairmanship of Professor Zenichi Yoshida of the chemical engineering department of Kyoto University, includes Wada, several other eminent molecular biologists, medical researchers, the director of the Takasaki Research Institute of the Atomic Energy Research Institute and a commentator from Japan's national television network, NHK.

During the next year, the subcommittee will chart policy, and the working group, composed of fifteen scientists including Tasuku Honjo of Kyoto University and Kenichi Matsubara of Osaka University, will draw up a detailed research programme.

Among the issues to be resolved are the relative weights to be placed on mapping and sequencing, and the priority of genes to be sequenced. Members of the subcommittee and the working group will visit the Seiko and Fuji Film factories to see the automatic DNA-sequencing machine.

There have been suggestions that sequencing of the human genome should form part of the Human Frontiers Science

$$
\text { But there MUST be a gene for }
$$
Economic Growth!

Program being organized by the Ministry of International Trade and Industry, the Science and Technology Agency and five other ministries (see Nature 326,$8 ; 1987$ ). But Wada, who chairs one of the Frontiers working groups, does not expect genome sequencing to figure prominently in Frontiers, although the development of DNAsequencing machines may well form part of the programme. The present feasibility study, on the other hand, is devoted specifically to sequencing of the human genome. David Swinbanks

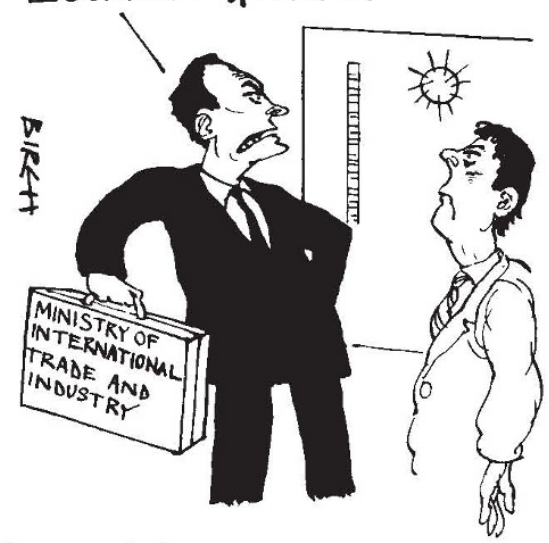

to have cures for almost any disease, including AIDS (acquired immune deficiency syndrome), but nobody has bothered to evaluate these claims scientifically, says Satyavati. Because modern drug research is a gamble and Indian drug companies lack resources, priority has been given to testing existing herbal cures.

One traditional treatment under evaluation at four ICMR centres is non-surgical treatment of anal fistula using a thread medicated with herbs described in Ayurveda. Called the 'kshaarasootra' technique, it has so far been used to treat more than 2,000 cases. According to Satyavati, patients now demand this treatment in preference to surgery. It has also become popular in Sri Lanka since Sri Lankan surgeons saw a demonstration in New Delhi.

Other traditional remedies under scrutiny by ICMR are those for filariasis, jaundice, urolithiasis, diabetes and bronchial asthma. Also under clinical trial is the herb 'banjari' (Vicca indica) used by tribals of Bihar as an abortifacient. An ayurvedic therapy for rheumatoid arthritis has also recently been clinically evaluated under a project sponsored by the World Health Organisation.

The health ministry, on its own, has been spending some US\$100 million a year in promoting research on indigenous medicines. One outcome is a herbal preparation for malaria caused by Plasmodium vivax. Eight Indian companies have been licensed to manufacture this drug, which is made available through the ministry's health delivery network. The Unani researchers also claim a cure for vitiligo, white skin patches caused by loss of pigmentation.

A promising anti-cancer drug derived from the plant Plumbago zyalanica is being evaluated by biochemists at Captain Srinivasamoorthy Drug Research Institute in Madras, as well as at the National Cancer Institute in the United States. The compound called plumbagin has been shown to reduce tumour growth in rats.

The government has encouraged research in indigenous systems of medicine by establishing separate national institutes for Ayurveda and Unani. Research councils have been set up for drugs research, drug standardization and a survey of medicinal plants.

According to the health ministry, "more and more people are taking to traditional systems". Among the reasons are the inherent faith of Indians that herbs have no side-effects, the rampant adulteration of modern drugs sold in drug stores and the rising cost of hospital treatment. At Chittur, in Andhra Pradesh state, a family of traditional healers who set broken bones using a herbal paste attract more patients in a day than the wellequipped orthopaedic wards of government hospitals in any city in India.

K.S.Jayaraman 